\title{
ADSORPSI ZAT WARNA METHYLENE BLUE MENGGUNAKAN ABU ALANG-ALANG (Imperata cylindrica) TERAKTIVASI ASAM SULFAT
}

\author{
Indah Riwayati", Ni'matul Fikriyyah dan Suwardiyono \\ Jurusan Teknik Kimia, Fakultas Teknik, Universitas Wahid Hasyim Semarang \\ Jl. Menoreh Tengah X/22, Sampangan, Semarang 50236 \\ *Email : indahriwayati@unwahas.ac.id
}

\begin{abstract}
Abstrak
Salah satu masalah dalam perkembangan industri kimia adalah pencemaran oleh limbah. Methylen blue merupakan zat pewarna tekstil dalam industri dan menjadi salah satu sumber pencemar lingkungan. Metode adsorpsi menggunakan abu alang-alang (Imperata cylindrica)merupakan salah satu upaya untuk menurunkan konsentrasi methylene blue. Penelitian ini bertujuan untuk mengetahui pengaruh rasio pH, waktu kontak dan massa adsorben terhadap adsorpsi oleh abu alang-alang (Imperata cylindrica). Metode penelitian ini meliputi 3 tahap. Tahap preparasi adsorben,adsorpsi, dan analisis Spektrofotometri UV-Vis. Proses adsorpsi dilakukan dengan variasi rasio pH 3-10. variasi waktu kontak 15-90 menit dan massa adsorben 0,5; 1; 1,5; 2; 2,5 dan 3 gram. Hasil penelitian menunjukkan kondisi terbaik adsorpsi terjadi pada pH 3, waktu kontak 75 menit, dan massa adsorben 1 gram dengan kapasitas adsorpsi sebesar 0,4844 $\mathrm{mg} / \mathrm{g}$.
\end{abstract}

Kata kunci : adsorben, adsorpsi, silikon dioksida, methylene blue, abu alang-alang

\section{PENDAHULUAN}

Industri kimia berkembang pesat seiring dengan pertambahan jumlah penduduk dunia. Industri yang menggunakan bahan pewarna sintetik dalam proses pembuatan produknya juga semakin meningkat. Industri yang menggunakan bahan pewarna sintetik antara lain kertas, obat-obatan, makanan, kulit, kosmetik, percetakan dan karet (Gong dkk., 2005; Hassan dkk., 2017). Pewarna sintetik mengandung senyawa dengan struktur molekul yang bersifat aromatik komplek, sehingga sulit untuk terurai secara alami ketika dibuang ke lingkungan (Kumar dkk., 2011).

Bahan pewarna dalam limbah akan menimbulkan masalah lingkungan. Limbah dengan warna yang pekat dan tingkat chemical oxygen demand (COD) yang tinggi akan meracuni kehidupan dalam perairan karena sifat molekulnya senyawa di dalamnya yang dapat mengikat ion logam (Sharma dkk., 2009). Beberapa jenis pewarna sintetik yang dipergunakan dalam industri bersifat stabil, tidak mengalami oksidasi dan tidak terpengaruh oleh cahaya serta tahan terhadap proses peruraian aerobik (Mohan dkk., 2002). Salah satu senyawa yang banyak dipergunakan dalam industri pewarnaan kain, kulit dan percetakan adalah methylen blue (Wang dkk., 2008).

Methylen blue merupakan salah satu senyawa pewarna yang larut di dalam air, bersifat kationik dan sering dipergunakan dalam bidang kimia, biologi, ilmu pengobatan dan industri pewarnaan. Pewarna ini tidak terlalu beracun bagi manusia, tetapi dapat menyebabkan iritasi mata, iritasi kulit, efek sistematik termasuk perubahan darah. Selain itu paparan senyawa ini pada tingkat tertentu dapat menyebabkan muntah, mual, diare, pusing, keringat berlebih dan radang pencernaan (Sen dkk., 2011; Tsai dkk., 2009).

Berbagai cara dipergunakan untuk mengolah limbah dengan kandungan zat pewarna sintetik, diantaranya dengan metode biologi, fisika dan kimia meliputi adsorpsi, biosoprsi, koagulasi/flokulasi, oksidasi lanjut, ozonisasi, filtrasi membran dan ekstraksi cair cair. Kelebihan dan kekurangan masing-masing metode telah banyak dibahas (Salleh dkk., 2011). Adsorpsi merupakan salah satu metode fisika yang banyak dipergunakan untuk mengolah limbah dengan kandungan zat pewarna karena mempunyai sifat mudah dipergunakan, efisien dan rendah kebutuhan energi, serta dapat mempergunakan berbagai bahan jenis adsorben (Teng dan Low, 2012; Liu dkk., 2012).

Saat ini telah banyak dikembangkan penelitian untuk memperoleh bahan adsorben yang relatif lebih mudah dibandingkan dengan karbon aktif.Adsorbent dapat dibuat dari bahan organik seperti rumput, daun, bunga, kulit buah yang tersedia dalam jumlah banyak. Sementara bahan organik padat yang telah diteliti untuk dijadikan adsorben diantaranya, pelepah kelapa (Hameed dkk., 2008), kulit hazelnut (Dogan 
dkk., 2009), kulit padi (Chowdhury dkk., 2011), cogongrass (Li dkk., 2013). Cogongrass atau alang alang (Imperata cylindrical) merupakan tanaman gulma pada lahan pertanian.

Alang alang dapat dipergunakan sebagai adsorben yang mampu menyerap beberapa jenis bahan seperti minyak (Ibrahim dkk., 2018), methylene blue (Su dkk., 2014; huda dkk., 2018) dan kalsium (Mardina dkk., 2012).

Abu alang-alang berpotensi untuk menjadi adsorben karena memiliki senyawa aktif berupa senyawa silikon dioksida $\left(\mathrm{SiO}_{2}\right)$. Senyawa yang terkandung dalam abu memiliki gugus silanol ( $\equiv \mathrm{Si}-\mathrm{OH})$ dan siloksan ( $\mathrm{Si}$ i-O-Si $\Rightarrow$ yang merupakan situs aktif yang mampu bertindak sebagai adsorben karena memiliki atom oksigen $\left(\mathrm{O}^{-}\right)$yang cukup reaktif sehingga mampu mengikat atom $\mathrm{N}^{+}$yang terdapat pada methylene blue. Silikon dioksida memiliki struktur ikatan kovalen raksasa yang mampu menampung adsorbat yang diserap dengan jumlah banyak (Pujiana, 2014).

Penelitian ini bertujuan untuk menganalisa pengaruh parameter proses adsorbsi methylene blue dengan menggunakan abu alang-alang yang sudah dimodifikasi dengan menggunakan asam.

\section{METODOLOGI}

\subsection{Bahan Penelitian}

Bahan-bahan yang digunakan dalam penelitian ini adalah abu alang-alang yang diperoleh dari pinggir sungai di Menoreh Tengah Sampangan, Semarang, Methylene blue, $\mathrm{H}_{2} \mathrm{SO}_{4}$ dan aquadest.

\subsection{Peralatan}

Alat yang digunakan yaitu Oven, stirrer magnetic, neraca analitik, ayakan120 mesh, corong, vakum drying, mortar, cawan porselin, peralatan gelas (beaker glass, pipet volume, labu takar, gelas ukur, erlenmeyer). Untuk analisis hasil adsorpsi digunakan spektrofotometer UV-Vis.

\subsection{Prosedur Penelitian}

\subsubsection{Persiapan Bahan Baku}

Sampel rumput alang-alang dicuci bersih kemudian dikeringkan di bawah sinar matahari hingga rumput alang-alang kering.Selanjutnya dilakukan pembakaran kemudian sampel abu alang-alangyang telah dibakar kemudian dihaluskan menggunakan mortar sampai halus dan kemudian diayak dengan ukuran partikel 120 mesh. Serbuk abu alang-alang ini sebagai adsorben tanpa aktivasi.

\subsubsection{Aktivasi Adsorben}

Larutan $\mathrm{H}_{2} \mathrm{SO}_{4} 2 \%$ sebanyak $100 \mathrm{~mL}$ ditambahkan ke dalam 100 gram abu alangalang. Abu direndam selama 24 jam, kemudian disaring menggunakan kertas saring. Residu yang didapat kemudian dikeringkan dalam oven pada suhu $60{ }^{\circ} \mathrm{C}$ dengan waktu pemanasan 24 jam. Residu dicuci sampai filtratnya mempunyai $\mathrm{pH}$ 7. Setelah dicuci abu dikeringkan dalam oven pada suhu $105{ }^{\circ} \mathrm{C}$ selama 24 jam.

\subsubsection{Adsorpsi Metylene blue}

Adsorpsi dilakukan dengan menimbang adsorben masing-masing tanpa aktivasi dan yang teraktivasi sebanyak 0,5 gram. Kemudian dimasukkan ke beaker glass berukuran $100 \mathrm{~mL}$ yang ditambah $50 \mathrm{~mL}$ larutan Methylene blue dengan konsentrasi $5 \mathrm{mg} / \mathrm{L}$. Selanjutnya diatur sesuai kondisi percobaan dan dilakukan pengadukan menggunakan stirrer magnetic. Hasil adsorsorpsi kemudian di saring, filtratnya dianalisis menggunakan spektrofotometer UVVis pada panjang gelombang $653 \mathrm{~nm}$. Dalam penelitian ini menggunakan tiga variabel yaitu optimasi rasio $\mathrm{pH}$, waktu kontak dan massa adsorben.

\subsubsection{Penentuan pH Terbaik Adsorpsi}

Larutan Methylene blue dengan konsentrasi $5 \mathrm{mg} / \mathrm{L}$ sebanyak $50 \mathrm{~mL}$ diatur $\mathrm{pH}$ nya dengan menggunakan $\mathrm{NaOH}$ dan $\mathrm{HCl}$. Variabel $\mathrm{pH}$ yang dipergunakan adalah $3,4,5,6,7,8,9$, dan 10. Ditambahi dengan abu alang alang sebanyak 0,5 gram. Campuran diaduk menggunakan magnetik stirrer selama 15 menit pada suhu ruang. Setelah itu, filtrat disaring menggunakan kertas saring Whatman. Konsentrasi Methylene blue sebelum dan sesudah adsorpsi dianalisis menggunakan Spektrofotometri UV-Vis. Kemudian dilakukan perhitungan:

a.) Persentase penyisihan adsorpsi.

Persentase penyisihan adsorpsi dapat dihitung dengan rumus :

$\%=\left(\frac{\mathrm{C}_{9}-\mathrm{C}_{2}}{\mathrm{C}_{0}}\right) \times 100 \%$

Keterangan :

$\%=$ persentase adsorpsi

$\mathrm{C}_{0} \quad=$ Konsentrasi awal larutan $(\mathrm{mg} / \mathrm{L})$

$\mathrm{C}_{\mathrm{a}} \quad=$ Konsentrasi akhir larutan $(\mathrm{mg} / \mathrm{L})$

b.) Kapasitas adsorpsi.

Kapasitas adsorpsi dapat dihitung dengan rumus : 
$Q=\frac{Y\left(C_{0}-C_{2}\right)}{\text { m }}$

$\mathrm{Q}=$ Kapasitas adsorpsi per bobot adsorben $(\mathrm{mg} / \mathrm{g})$

$\mathrm{V}=$ Volume larutan $(\mathrm{L})$

$\mathrm{C} 0=$ Konsentrasi awal larutan $(\mathrm{mg} / \mathrm{L})$

$\mathrm{Ca}=$ Konsentrasi akhir larutan $(\mathrm{mg} / \mathrm{L})$

$\mathrm{m}=$ Massa adsorben $(\mathrm{g})$

\subsubsection{Penentuan Waktu Kontak Terbaik Adsorpsi}

Sebanyak $50 \mathrm{ml}$ larutan metilen biru konsentrasi $5 \mathrm{mg} / \mathrm{L}$, diatur pada $\mathrm{pH}$ optimum. Ditambahkan 0,5 gram adsorbent abu alang alang, diaduk dengan menggunakan magnetik stirer dengan waktu sesuai variabel, yaitu 15 ; 30; 45; 60; 75; dan 90menit.

\subsubsection{Penentuan Massa Adsorben Terbaik}

Sebanyak $50 \mathrm{~mL}$ larutan methylene bluedengan konsentrasi $5 \mathrm{mg} / \mathrm{L}$ ditambah dengan adsorbent abu alang alang sesuai variabel massa yang ditambahkan sebanyak 0,5 ; $1 ; 1,5 ; 2 ; 2,5$ dan 3 gram. Kemudian larutan di atur pada kondisi $\mathrm{pH}$ terbaik. Diaduk dengan menggunakan magnetik stirer sesuai dengan variabel waktu terbaik yang telah diperoleh sebelumnya.

\section{HASIL DAN PEMBAHASAN}

\section{1 pH Terbaik Adsorpsi}

Pengaruh $\mathrm{pH}$ terhadap presentase penyisihan warna methylen blue oleh adsorben Abu Alang-alang teraktivasi dapat dilihat pada gambar 1. $\mathrm{pH}$ merupakan variabel yang sangat berpengaruh dalam proses adsorpsi dengan adsorben dari biomaterial. Pengaruh nilai $\mathrm{pH}$ dipelajari pada nilai $\mathrm{pH} 3,4,5,6,7,8,9$ dan 10 . Pada Gambar1. menunjukkan bahwa kapasitas Adsorpsi methylene blue menurun dengan semakin tingginya $\mathrm{pH}$. Kapasitas adsorpsi abu alang alang teraktivasi terhadap metilen biru cenderung lebih besar pada medium dengan $\mathrm{pH}$ rendah dibandingkan pada medium $\mathrm{pH}$ tinggi.

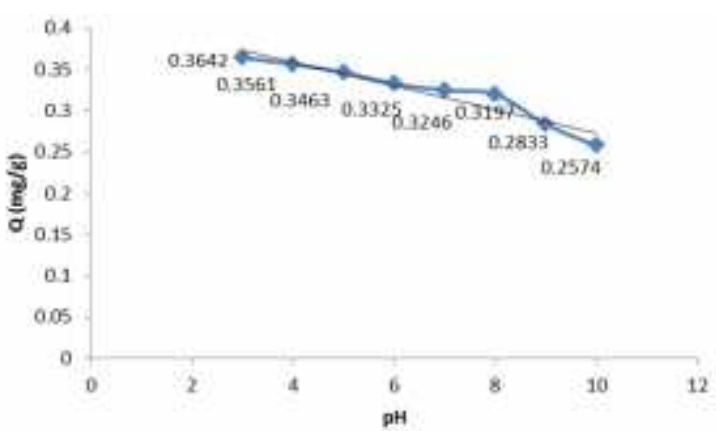

Gambar 1. Pengaruh pH terhadap kapasitas adsorpsi (waktu kontak = 15 menit; volume larutan $50 \mathrm{ml}$ )

Adsorpsi pada $\mathrm{pH}$ tinggi menurun karena luas permukaan adsorben lebih banyak terprotonisasi serta terjadi kompetisi adsorpsi yang terjadi antara ion $\mathrm{H}+$ dan ion metilen biru bebas serta ion $\mathrm{OH}$ - terhadap situs-situs ikatannya. Oleh karena itu ion $\mathrm{H}+$ bereaksi dengan gugus anionik fungsional pada permukaan adsorben sehingga mengurangi jumlah ion metilen biru yang dapat diikat (Jirekar dkk., 2014).

Pada $\mathrm{pH}$ rendah (kurang dari 5) ion metilen biru dapat masuk ke dalam struktur pori adsorbent, sedangkan pada $\mathrm{pH}$ yang tinggi 9lebih dari 7) bentuk ion zwitter dari metilen biru meningkatan agregasi untuk membentuk molekul yang lebih besar (dimer) sehingga lebih sulit untuk masuk ke pori adsorben. Penggumpalan yang lebih besar dari ion zwitter metilen biru disebabkan dapat oleh interaksi daya tarik elektrostatik antara gugus ionik dan monomer (Arivoli dkk., 2010).

Adsorpsi methylene blue terbaik terjadi pada pH 3 dimana terjadinya kesetimbangan antara zat warna dengan ion hidroksil didalam larutan, sehingga zat warna mampu menangkap ion hidroksil yang ditambahkan. Adsorben abu alang alang teraktivasiterus mengalami penurunan kapasitas adsorpsi pada $\mathrm{pH} 4$ sampai $\mathrm{pH}$ 10. Pada $\mathrm{pH}$ asam terjadi interaksi antara atom oksigen yang bermuatan negatif pada senyawa oksida silikon yang terdapat pada abu alang-alang akan mengikat atom $\mathrm{N}$ yang bermuatan positif pada senyawa methylene blue sehingga terjadi penyerapan methylene blue oleh senyawa aktif $\mathrm{SiO}_{2}$ (Alzaydien, 2009). Sedangkan pada $\mathrm{pH}$ basa dapat mengganggu peningkatan protonasi pada larutan methylene blue. Hal ini dikarenakan ion $\mathrm{OH}^{-}$yang terlalu banyak dalam larutan tidak mampu ditangkap oleh zat warna sehingga masih banyak ion $\mathrm{OH}^{-}$ yang bebas di dalam larutan yang menyebabkan 
terjadinya kompetisi antara zat warna dengan ion $\mathrm{OH}^{-}$bebas untuk menempati permukaan abu yang akan menurunkan daya adsorpsi zat warna.

\subsection{Waktu Kontak Terbaik Adsorpsi}

Pengaruh waktu kontak terhadap kapasitas adsorpsi methylene blue oleh adsorben abu alang-alang teraktivasi seperti gambar 2.

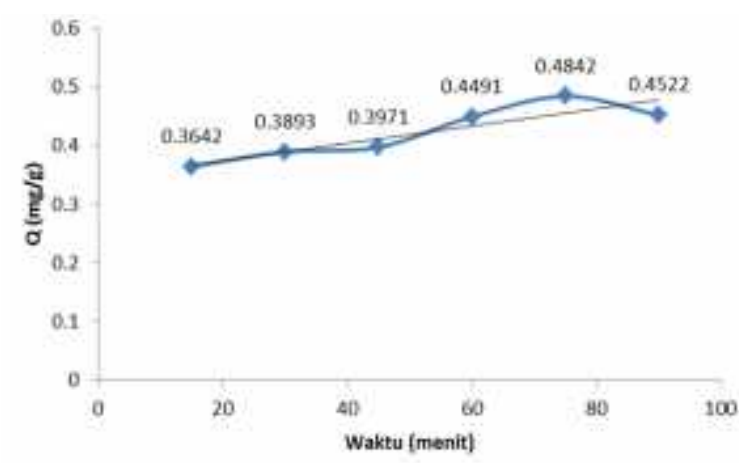

Gambar 2. Pengaruh waktu terhadap kapasitas adsorpsi (Kondisi : $\mathbf{p H}=3$; waktu kontak = 75 menit; volume larutan $50 \mathrm{ml}$ )

Dari grafik pengaruh waktu kontak pada adsorpsi methylene blue oleh abu alang-alang teraktivasi menunjukkan bahwa semakin lama waktu kontak adsorpsi maka semakin besar pula methylene blue yang teradsopsi. Hasil penelitian menunjukkan bahwa abu alang-alang teraktivasi dalam mengadsorpsi methylene blue secara optimal berada pada waktu 75 menit dengan kapasitas adsorpsi 0,4842 mg/g. Hasil ini diperkuat dengan hasil penelitian Falahiyah (2015)untuk adsordpsi methylen blue dengan abu serabut dan tempurung kelapa menghasilkan waktu optimum 75 menit.

Pada waktu 15 sampai 75 menit terjadi peningkatan kapasitas adsorpsi namun setelah waktu 90 menit terjadi penurunan kapasitas adsopsi pada adsorben abu alang-alang teraktivasi. Adsorpsi dapat terjadi melalui 2 tahap proses, tahap pertama molekul pewarna mencapai lapisan batas, kemudian menyebar ke permukaan serta masuk ke dalam pori adsorbent. Tahap berikutnya terjadi pelepasan zat teradsorpsi secara cepat karena pori adsorbent telah mengalami kejenuhan. Dua tahapan proses ini yang menyebabkan proses adsorpsi memerlukan waktu yang relatif lama. Secara umum, laju adsorpsi akan meningkat pada awal proses dan menurun secara bertahap sampai pada titik kesetimbangan. Hal ini terjadi karena masih banyak pori yang tersedia untuk tempat masuknya adsorbate pada awal proses dan semakin menurun jumlahnya seiring berjalannya waktu. Pori yang tersisa pada permukaan adsorben sulit untuk ditempati karena gaya tolak menolak antara molekul adsorbate pada fase padatan dan bulk (Bazrafshan, 2012).

\subsection{Rasio Massa Adsorben Terbaik Adsorpsi}

Pengaruh massa terhadap kapasitas adsorpsi methylene blue oleh adsorben abu alang-alang teraktivasi seperti gambar 3

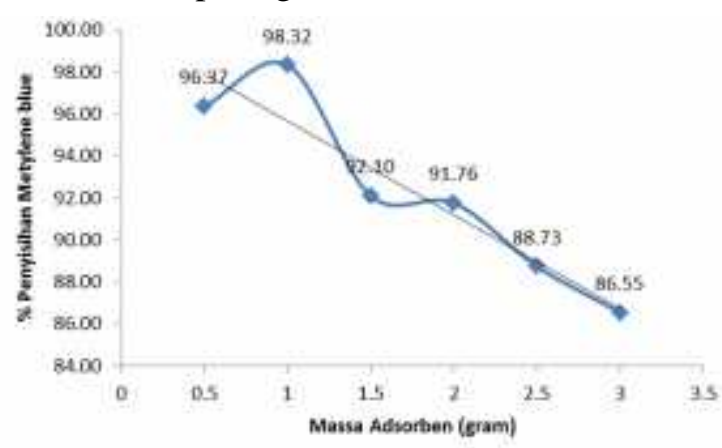

Gambar 3. Pengaruh massa terhadap \% Penyisihan methylene blue (kondisi : $\mathbf{p H}=3$; waktu kontak = 15 menit; volume larutan 50 ml)

Pada umumnya bahwa semakin besar massa adsorben yang digunakan maka semakin besar kapasitas dan efisiensi adsorpsi. Namun, pada penelitian ini pengaruh massa adsorben terhadap persentase (\%) penyisihan methylene blue (Gambar 3.) menunjukkan bahwa pada massa 0,5 gram sampai 1 gram efisiensi adsorpsi mengalami kenaikan. Pada penambahan massa 1 gram memberikan nilai maksimal dengan persentase adsorpsi methylene blue sebesar 98,32\%.

Peningkatan penyisihan warna dengan meningkatnya massa adsorben terjadi karena luas permukaan menjadi lebih besar dan ketersediaan situs-situs aktif adsorpsi yang lebih banyak. Pada massa adsorben yang kecil, permukaan adsorben menjadi jenuh dengan adsorbat methylene blue sedangkan sisa konsentrasi zat warna dalam larutan masih besar sehingga penyisihan relatif kecil (Romandhani, 2017). Tetapi, untuk massa 1,5 sampai 3 gram kapasitas adsorpsinya semakin menurun. Hal ini disebabkan karena pada massa 1,5 gram sampai 3 gram masih banyak zat aktif yang belum berikatan dengan adsorbat, sehingga efisiensi adsorpsi semakin kecil, sedangkan pada massa 1 gram seluruh 
permukaan adsorben telah terikat dengan adsorbat.

Sementara itu pengaruh massa adsorben ditunjukkan pada gambar 4. menunjukkan kenaikan massa adsorben (0,5-3 g/L) mengakibatan penurunan kapasitas adsorpsi.

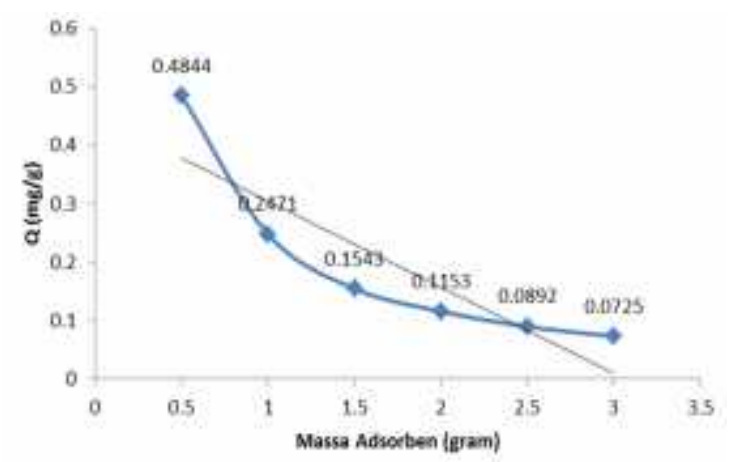

Gambar 4. Pengaruh massa terhadap kapasitas adsorpsi(Kondisi : $\mathbf{p H}=3$; waktu kontak = 75 menit; volume larutan $50 \mathrm{ml}$ )

Kapasitas adsorpsi paling besar $(0,4844$ $\mathrm{mg} / \mathrm{g}$ ) tercapai dengan massa adsorben sebesar 0,5 gram. Penurunan kapasitas adsorpsi untuk massa adsorben yang lebih besar terjadi karena dengan meningkatnya massa adsorben maka jumlah situs-situs jenuh persatuan massa adsorben menjadi berkurang. Hasil ini juga diperkuat oleh hasil penelitian Ranita dkk., (2017) bahwa dengan semakin bertambahnya massa adsorben yang digunakan maka kemampuan adsorpsi semakin kecil. Hal ini disebabkan adsorbat yang digunakan terbatas yang menyebabkan massa adsorben saling tumpang tindih atau berebutan, sehingga adsorbat terbatas gerakannya untuk merebutkan permukaan.Persen adsorpsi akan meningkat seiring bertambahnya jumlah adsobent, tetapi satuan adsoprsi menurun. Hal ini dapat disebabkan oleh karena terjadinya tumpang tindih atau penggumpalan luas permukaan adsorbent yang tersedia untuk metil biru. Selain itu terjadi peningkatan panjang jalur difusi (Lata dkk., 2007).

\section{KESIMPULAN}

Berdasarkan penelitian yang telah dilakukan dapat disimpulkan bahwa $\mathrm{pH}$, waktu kontak, massa adsorben berpengaruh terhadap adsorpsi menggunakan abu alang-alang teraktivasi $\mathrm{H}_{2} \mathrm{SO}_{4}$. Kondisi terbaik terjadi pada pH 3, waktu 75 menit, dan massa adsorben 0,5 gram dengan kapasitas adsorpsi 0,4844 mg/g.

\section{DAFTAR PUSTAKA}

Alzaydien, A.S., Adsorption of Methylene blue from aqueous solution onto a low-cast natural Jordanian tripoli. Am. J. Environ. Sci., 5(3), 197-208(2009)

Arivoli, S., Hema, M., Parthasarathy, S., Manju, N., 2010, Adsorption Dynamic of Methylene blue by Acid Activated Carbon, Journal of chemical and Pharmaceutical Research, Vol.2 No. 5, pp. 626-641

Bazrafshan, E., Mostafapour, F., K., Zazoulu, M.,A., 2012, Methylene blue (cationic dye) adsorption into Salvadora persica stems ash, African Journal of Biology Vl. 11(101), pp. 16661-16668

Chowdhury, S., Mishra, R., Saha, P., \& Kushwaha, P. (2011).Adsorption thermodynamics, kinetics and isosteric heat of adsorption of malachite green onto chemically modified ricehusk. Desalination, 265(1-3), 159-168. Dogan, M., Abak, H., \& Alkan, M. (2009). Adsorption of methylene blue onto hazelnut shell: kinetics, mechanism and activation parameters. Journal of Hazardous Materials, 164(1), 172-181.

Falahiyah, 2015, Adsorpsi methylene blue menggunakan abu dari sabut dan tempurung kelapa teraktivasi asam sulfat, Skripsi,Jurusan kimia, Fakultas Sains dan Teknologi, Universitas Islam Negeri Maulana Ibrahim Malang.

Gong, R. M., Li, M., Yang, C., Sun, Y. Z., \& Chen,J.(2005). Removal of cationic dyes from aqueous solutionby adsorption on peanut hull. Journal of HazardousMaterials, 121(1-3), 247-250. doi:10.1016/j.jhazmat.2005.01.029.

Hameed, B. H., Mahmoud, D. K., \& Ahmad, A. L.(2008).Equilibrium modeling and kinetic studies on the adsorption of basic dye by a low-costadsorbent: coconut (Cocos nucifera) bunch waste. Journal of HazardousMaterials, 158(1),65-72.

Huda, T. Dan Yulitaningtyas, T.K., Kajian Adsorpsi Methylene Blue Menggunakan Selulosa dari Alang alang, Indonesian Journal of Chemical Analysis. ISSN 26227401. Pp. 09-19

Ibrahim, S., Baharuddin, S.N.I., Ariffin, B., Hanafiah, M.A.K.M., Kantasamy, N., 2018, Cogon Grass for Oil Sorption: Characterization and Sorption Studies, Key 
Engineering Material, ISSN:1662-9795, Vol. 775, pp. 359-364

Jirekar, D.B, Pathan, A.A, Farooqui, M., 2014, Adsorption Studies of methylene Blue Dye from Aqueous Solution onto Phaseolus aureus Biomaterials, Orintal Journal of Chemistry, ISSN: 0970-020 X, Vol. 30, No. 3, pp:1263-1269

Lata, H., Garg, V.K. and Gupta, R.K. (2007) Removal of a basic dye from aqueous solution by adsorption using Parthenium hysterophorus: An agricultural waste. Dyes and Pigments, 74, 653-658.

Li, Z. M., Teng, T. T., Alkarkhi, A. F. M., Rafatullah, M., \&Low, L. W. (2013). Chemical modification of Imperata cylindricalleaf powder for heavy metal ion adsorption. Water, Air, and Soil Pollution, 224(4), 1505.

Liu, Y., Wang, J. T., Zheng, Y., \& Wang, A. Q. (2012).Adsorptionof methylene blue by kapok fiber treated by sodium chlorite optimized with response surface methodology. ChemicalEngineering Journal, $184, \quad 248-255$. doi:10.1016/j.cej.2012.01.049.

Hassaan, M. A., El Nemr, A., (2017). Health and EnvironmentalImpacts of Dyes: Mini Review, American Journal ofEnvironmental Science and Engineering., 1. 64-67

Mardina, P., Purba, N.J., Permatasari M.A., 2012, Tanaman alang-alang sebagai Biomassa adsorben untuk penurunan kadar kalsium, Ekuilibrium. Vol. 11. No. 2. Hal: 47-50

Mohan, D., Singh, K. P., Singh, G., \& Kumar, K. (2002). Removalof dyes from wastewater using fly ash, a low-cost adsorbent.Industrial \& Engineering Chemistry Research, 41(15),3688-3695. doi:10.1021/Ie010667+.

Kumar, P. , Ramalingam, S., Sathishkumar, S., K., (2011). Removal of methylene blue dye from aqueous solution by activatedcarbon prepared from cashew nut shell as a new lowcostadsorbent, Korean J. Chem. Eng., 28. 149-155.

Pujiana, N. 2014. Adsorpsii Methylene blue Menggunakan Abu Sabut Tempurung Kelapa Teraktivasi Natrium Klorda (NaCl) sebagai Adsorben. Skrpsi. Malang: Jurusan Kimia Fakultas Sains dan Teknologi UIN Maulana Malik Ibrahim Malang.
Ranita, dkk., (2017), Pembuatan Biosorben Dari Biji Pepaya (Carica papaya L) Untuk penyerapan zat warna,Jurnaal Teknik Kimia USU, Vol, 6 No.2. Juni 2017.

Romandhani, S., (2017), Pemanfaatan ossis ayam (Gallus gallus) sebagai penurun konsentrasi methylene blue dalam larutan menggunakan metode adsorpsi, Laporan Penelitian Jurusan Teknik Kimia, Fakultas Teknik, Universitas Wahid Hasyim Semarang

Salleh, M.A.M., Mahmoud, D.K., Karim, W.A.W.A., Idris, A., 2011.Cationic and anionic dye adsorption by agricultural solid wastes:acomprehensive review. Desalination 280, 1-13.

Sen, T. K., Afroze, S., \& Ang, H. (2011). Equilibrium, kineticsand mechanism of removal of methylene blue fromaqueous solution by adsorption onto pine cone biomass

of Pinus radiata. Water, Air, \& Soil Pollution, 218(1-4),499-515.

Sharma, Y. C., Uma, \& Upadhyay, S. N. (2009). Removal of acationic dye from wastewaters by adsorption on activatedcarbon developed from coconut coir. Energy \& Fuels, 23,2983-2988. doi:10.1021/Ef9001132.

Su, C.X., Teng, T.T, Alkarkhi, A.F.M., Low, L.W., 2014, Imperata cylindrica (Cogongrass) as an Adsorbent for methylene Blue Dye Removal: Process Optimization, Water Air Soil Pollution. 225:1941

Teng, T. T., \& Low, L. W. (2012). Removal of dyes and pigmentsfrom industrial effluents. In S. K. Sharma \& R. Sanghi (Eds.),

Water treatment and pollution prevention: advances in research (pp. 64-93). New York: Springer.

Tsai, W. T., Hsien, K. J., \& Hsu, H. C. (2009). Adsorption of organiccompounds from aqueous solution onto the synthesized zeolite. Journal of Hazardous Materials, $166,635-641$.

Wang, X. S., Zhou, Y., Jiang, Y., \& Sun, C. (2008). The removalofbasic dyes from aqueous solutions using agricultural byproducts. Journal of Hazardous Materials, $\quad$ 157(2-3),374-385. doi:10.1016/j.jhazmat.2008.01.004 